\title{
La vacuna de varicela resulta efectiva en la práctica clínica
}

The efectiveness of the varicela vaccine in clinical practice. Vazquez M, Steinberg SP, Freudigman K et al.. N Eng J Med 2001; $344: 955$ 60 .

\section{Objetivo}

Evaluar la efectividad de la vacuna contra varicela aprobada en 1995 en EE.UU. para aplicación en susceptibles mayores de 12 meses.

Diseño

Estudio de caso-control.*

Lugar

New Haven, Connecticut, EE.UU.

\section{Pacientes}

Se seleccionaron dos controles por cada caso potencial, apareados de acuerdo a edad y centro pediátrico. Trescientos treinta casos potenciales de varicela y 500 controles fueron evaluados. Ambos grupos fueron tomados de la población de niños sanos con edades entre 13 meses y 16 años en el período comprendido entre marzo de 1997 y noviembre de 2000.

\section{Intervención}

Se identificaron los casos potenciales de varicela en los centros pediátricos y se los visitó al tercer, cuarto y quinto día de enfermedad. Se recolectaron muestras de las lesiones y se realizó PCR de las mismas. De todos los pacientes se obtuvo documentación escrita acerca del estado de vacunación.

\section{Medición de resultados principales}

Se evaluó si los casos y los controles habían tenido distinta exposición a la vacuna. Se clasificó la enfermedad mediante PCR positiva $(+)$, Negativa $(-)$ o indeterminada y la severidad clínica en leve, moderada y grave.

\section{Resultados Principales}

De los 330 casos potenciales de varicela 243 tuvieron PCR (+), es decir el $74 \%$. Estuvieron disponibles 389 controles para 202 de estos casos. De los 56 niños con varicela vacunados, el $86 \%$ tuvo enfermedad leve, mientras que solo el $48 \%$ de los 187 no vacunados tuvieron varicela leve $(p<0.001)$. De los 202 niños con varicela confirmada con PCR y los 389 controles, el $23 \%$ de los niños con varicela y el $61 \%$ de los controles habían recibido la vacuna. La efectividad global fue del $85 \%$ (IC95\% 78 a $90 \%$ p< $0.001)$. la efectividad para prevenir enfermedad moderada o severa fue del $97 \%$ (IC95\% 93 a 99\% p< 0.001). La efectividad fue similar en los niños de 5 a 10 años que en los mayores de 10 años y no varió en el análisis multivariable*. Desarrollaron varicela el $30 \%$ de los contactos con niños con PCR (+) y ninguno de los contactos con niños con PCR (-) o indeterminada. Estos resultados hacen presumir que los pacientes con PCR (-) o indeterminada no se trataron de verdaderas varicelas.

\section{Conclusión}

La vacuna para varicela de virus atenuados es altamente efectiva en la práctica clínica. La efectividad global es del $85 \%$. Otro dato de interés es que la mayoría de los casos entre los vacunados fueron leves.

\section{Comentario}

Cuando se evalúa una vacuna es importante tener en cuenta las fallas primarias (falta de respuesta) y secundarias (disminución del nivel de anticuerpos a lo largo del tiempo) a la misma. La eficacia clínica del $85 \%$ y la protección contra el $92 \%$ de las formas graves, parecerían indicar una respuesta inmunológica insuficiente en aquellos que desarrollan la enfermedad a pesar de estar vacunados, aunque sin falta total de respuesta. Con respecto a la falla secundaria la evaluación es más difícil ya que aún en países en donde se ha inmunizado por más tiempo, como por ejemplo Japón, siguen existiendo brotes por virus salvaje que podrían actuar como amplificación. Queda por lo tanto como interrogante si serán necesarias dosis de refuerzo cuando no haya epidemias anuales.

La varicela es una enfermedad que no causa sólo vesículas pruriginosas y unos días de ausencia escolar; también puede producir complicaciones graves como infecciones oportunistas por Streptococos y Estafilococos, cerebelitis, encefalitis y Herpes Zoster; algunas de las cuales aumentan su frecuencia con la edad. Aunque aun no se encuentra en el calendario nacional de vacunación en Argentina, numerosos estudios realizados en todo el mundo avalan la aplicación universal de la vacuna contra la misma.1-5 